\title{
Business process modelling and visualisation to support e-government decision making: Business/IS alignment
}

\author{
Sulaiman Alfadhel ${ }^{1}$, Shaofeng Liu ${ }^{1}$, Festus O. Oderanti ${ }^{2}$, \\ ${ }^{1}$ Plymouth Graduate School of Management, Plymouth University, UK \\ ${ }^{2}$ Hertfordshire Business School, University of Hertfordshire, UK \\ sulaiman.alfadhel@plymouth.ac.uk; shaofeng.liu@plymouth.ac.uk; \\ F.Oderanti@Herts.ac.uk
}

\begin{abstract}
Alignment between business and information systems plays a vital role in the formation of dependent relationships between different departments in a government organization and the process of alignment can be improved by developing an information system (IS) according to the stakeholders' expectations. However, establishing strong alignment in the context of the eGovernment environment can be difficult. It is widely accepted that business processes in the government environment plays a pivotal role in capturing the details of IS requirements. This paper presents a method of business process modelling through UML which can help to visualise and capture the IS requirements for the system development. A series of UML models have been developed and discussed. A case study on patient visits to a healthcare clinic in the context of eGovernment has been used to validate the models.
\end{abstract}

Keywords: IS requirements, process modelling and visualisation, goal modelling, UML, requirements elicitation.

\section{Introduction}

The trend toward the globalization of the business organization environment remains unabated and has generated profound renovations, both internal and external, as the 'majority of organizations seek to re-align or re-create their value chain while endeavoring to forge closer associations with their consumers and business partners. The term eGovernment refers to the use of information system (IS) services by government agencies that have the potential to transform relationships with industry, citizens and other arms of government [21]. IS technologies can serve a variety of different ends, such as better government services to citizens, enhanced interactions between government and business industry and the management of government administration [21, 24].

In response to or in anticipation of changes in their environment, the majority of organizations are deploying information systems for this purpose at a growing rate $[23,29]$. Consequently, this has raised a primary question fundamental to the current 
business paradigm: how can a business organization actually justify its information system investments in the context of contributing to business performance, be it in terms of efficiency, amplified market share, productivity or other indicators of organizational usefulness $[14,15,16]$ ?

However, the process of managing and providing IS services for any government is a difficult job, due to rapid changes in the government environment and a lack of alignment between various government departments and the IS department. Strong alignment between IS and other departments of government can achieve better administration and organizational performance in many ways, such as strategic, social, cultural and structural performance $[1,5,13]$.

The literature shows that researchers have studied alignment in different contexts, for example, the strategic differences between business and information systems, the structural differences between business and information systems, and the cultural differences between business and information systems [3, 4, 2]. One way of establishing strong alignment between IS and other government agencies is to develop IS in accordance with government expectations to ensure a system that meets the government's needs $[11,12,13]$.

System requirements engineering is the process of determining the government's perspective on the system, which helps developers design a system that accurately meets the government's needs. To obtain accurate system requirements, it is important to understand the business environment in which the system will be deployed. Therefore, business process modelling in the context of obtaining system requirements is required prior to developing the system [7, 30, 17]. This paper presents a method of modelling and analyzing business processes with the aim of deriving the system requirements from the business goals and developing a suitable ehealth system in the context of eGovernment.

\section{Related work}

Alignment is a procedure where two different groups, business and information system, are interconnected with each other and where information system aims to provide services at all levels of the business organization in order that the business goals and objectives of the organization are attained [7, 30]. However, alignment is not a single entity; it is a vague and ambiguous process that contains of several stages, each stage representing a precise part of the business organization. Moreover, literature shows that modeling business goals in context of alignment between business and information systems and e-government has not been addressed [28]. Only a few researchers have look at this issue in context of business goal modelling, together producing a good deal of work which include: I* [34], GOMS [36], Goalbased Workflow [35], and KASO [33].

The I* approach is based on a goal modelling in the context of eGovernment idea that enables information system analysts to inspect the business requirements at an early stage of system development. It needs the organization's actors to explain the business goals and business strategy. In this modelling approach, business organizational actors have their predefine business goals and beliefs and every actor is 
associated to one another [34]. The GOMS and Goal-based Workflow techniques propose a goal modelling methods for system requirements elicitations in regard to illuminating the business organizational objectives and to thoughtful the current organizational situation [35-36]. KAOS is a business goal-based technique for information system requirements engineering that addresses numerous requirements engineering features which include: system requirements elicitations, requirements analysis and requirements management. This technique also helps in the victorious completion of business requirements and helps to identify conflicts among IS and business sectors [33].

All these techniques have several drawbacks. First, the techniques are complex for information system analysts and developers to understand; also they provide lack of information on developing suitable information system for government sectors. Secondly, they do not offer sufficient information on business processes, as one business goal is a mixture of different sub-goals that need to be discovered in order to analyse the business goal entirely. Thirdly, the techniques are time consuming. In the latter part of the last century, with the quick increase in globalization in government and business sectors both need to move quicker and require quicker information system implementation, and have a strong association involving clear communication with information system.

\section{Methodology: business process modelling with UML}

Recent studies on alignment between business and eGovernment research suggest two main IS theories in the context of internal and external organizational issues, namely system theory and network theory [32]. System theory is the interdisciplinary theory of IS in general, with the aim of identifying system requirements patterns and clarifying principles that can be distinguished from, and functional for all types of IS at all nesting levels in all fields of IS research. This theory's main focus is on internal organisational relationships [32]. Network theory examines the business organizational structure in relation to the organizational social aspect. These theories tend to place more emphasis on the business structures and dynamics of social relationships.

However, due to the nature of this research, we use system theory to underpin this study. A system is a combination of subsystems or parts that are integrated to accomplish the overall business goals [28, 32]. Moreover, the system in an organization has numerous inputs, which go through several processes to obtain accurate outputs to achieve the overall system goals. An organization is made up of many departments or divisions, such as finance, marketing, administration etc. and each department requires system support to achieve common business goals. However, the nature of the business often changes which distributes alignment processes between business departments and IS [32]. Systems theory helps in the understanding of the different organizational factors that contribute towards strong alignment and helps to identify the system requirements from the business process.

Moreover, in this paper we have chosen the modelling method is because it helps to visualize the business process. Unified Modelling Language (UML) is a language 
is being used in an industry widely. It has wide-range of elements and diagrams and it is a rich graphical notation. In this paper, UML has been used to visualize and to identify the business goals and Microsoft Visio tool has been used to model the business process

\section{Models for alignment in eGovernment}

Information and communication technologies (ICT) and IS are increasingly playing a vital role in the success of any type of business organization in the information age. The impact of IS on numerous domains, such as education, medicine, business, engineering, government etc. $[27,25]$ has been enormous. However, rapid change in both ICT and IS fields and substantial enhancements in digital connectivity has forced governments to change their structure. This is why mostly governments these days are reconsidering the way they work and interact both internally and with external business organizations [29, 31].

Moreover, this rapid change in ICT and IS has also encouraged government organizations and associations to reassess their internal and external relationships and dealings [4, 21]. Therefore, alignment between IS and other government agencies is important to establish strong working relationships. One way of aligning IS with other agencies in the government is to develop a system in accordance with the government's needs. This is only possible if IS developers understand and analyze the government environment, activities and business processes, all of which must be considered before commencing the development phase of IS. This is why business process and goal modelling is required before IS implementation to ensure the provision of appropriate government services [23]. In this paper, we only deal with the derivation of IS requirements from the eGovernment process, which is level 2 of the method, therefore, this paper will not discuss level 1 of the model.

An e-health process in the context of eGovernment has been selected to evaluate this proposed method. As the e-health process in the eGovernment infrastructure is the entity that focuses on the government's objectives in relationships to provide better health care services, modelling the e-health process is a key step towards obtaining IS requirements from the health process as it shows how the government's goals in relation to e-health can be attained using a real scenario $[15,27]$. To model the e-health process, the well accepted UML technique, namely Business Process Modelling Notation (BPMN) $[32,33]$ has been used. The technique is widely used in the area of system analysis and development. It is now considered to be a standard modelling language that bridges the gap between the development process and the business model.

\subsection{Modelling eGovernment process}

The model used in this paper aims to assist eGovernment by helping e-health system developers better understand the eGovernment environment and to derive the system requirements from the eGovernment process and goals. The proposed model requires 
a clear understanding of e-health processes in regard to modelling e-health processes/goals and extracting the related goals effectively to generate e-health IS requirements. The model is categorized into two levels, as demonstrated in Figure 1.

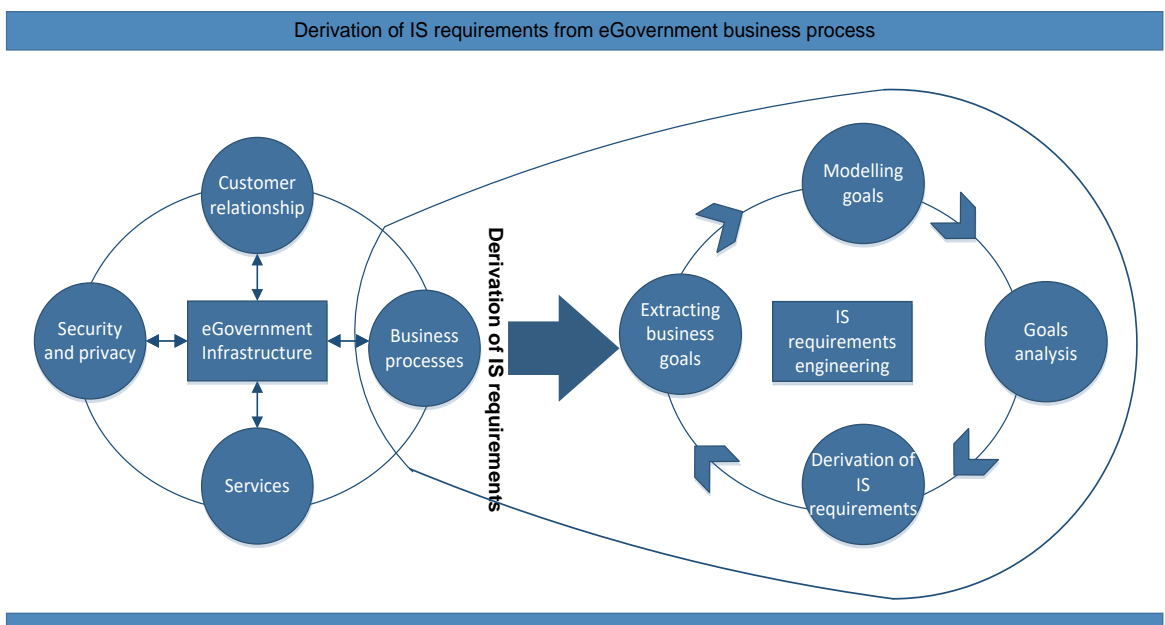

Figure 1: Business processes within eGovernment

The first level of the proposed model is derived from the existing literature, which is based on an understanding of eGovernment infrastructure [25, 21]. This infrastructure is divided into four phases, namely: security and privacy, customer relationship, eGovernment services and business processes. This level demonstrates the decision level of an eGovernment infrastructure and details the government's objectives, the government services and resources and the eGovernment strategies and processes in the form of a vision, goal, evaluation and targets of the government strategy.

Level 2 of the model defines the concept of modelling eGovernment processes to obtain, model and investigate e-health processes in the context of eGovernment and the development of an e-health system. This level explains how to attain IS requirements from the health processes that were obtained through modelling the eGovernment processes based on a thorough understanding of the healthcare environment. This level is divided into four phases: extracting business goals, modelling goals, goals analysis and derivation of IS requirements.

\subsection{Modelling e-health process}

Patient visits to a healthcare provider were used as the process to be modelled and to validate the proposed method, as shown in Figure 2. This process was implemented by the Ministry of eGovernment in Saudi Arabia, with the aim of improving the sharing of medical information among healthcare providers and the government so that e-health services could be improved in the kingdom. 


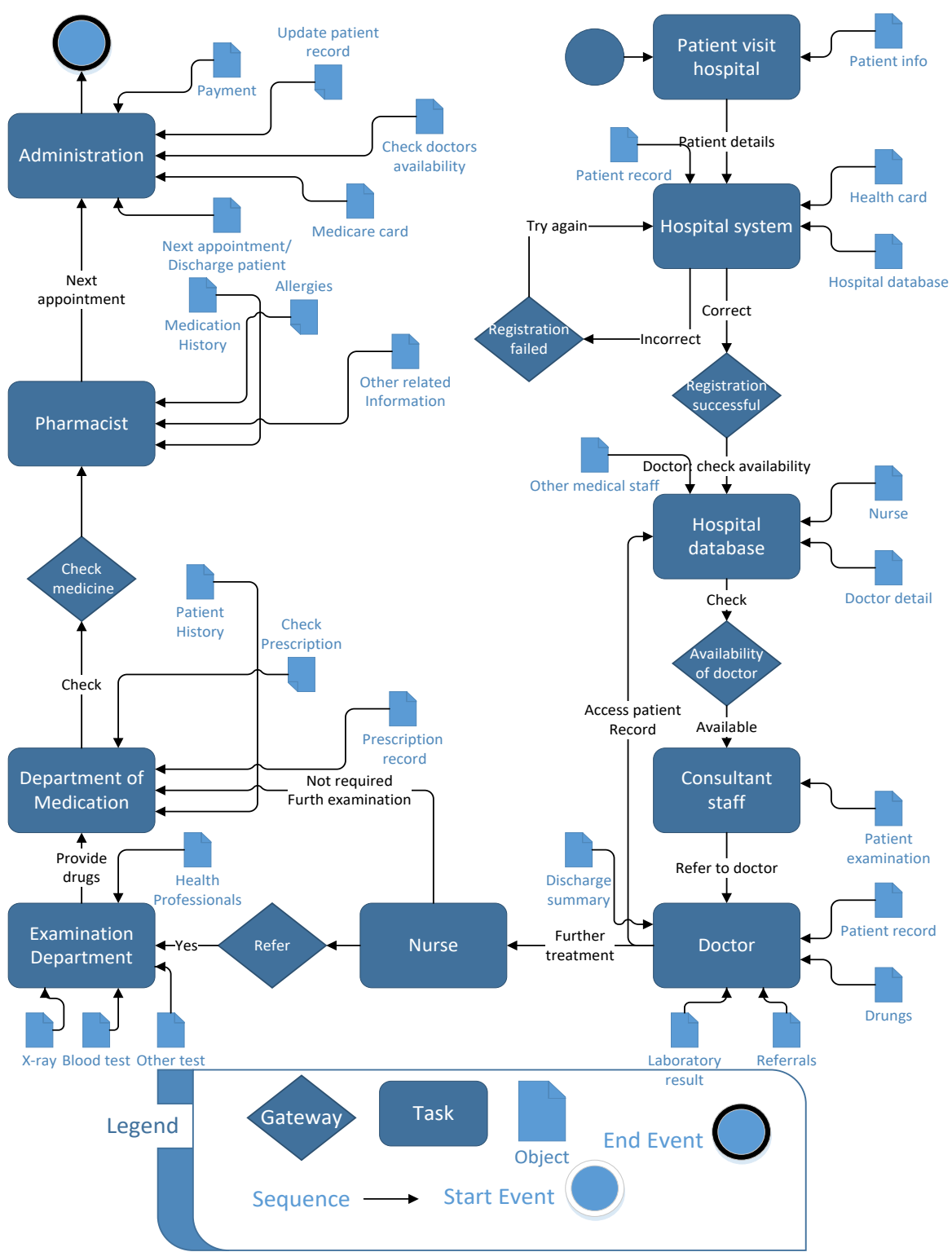

Figure 2: Process of e-health

As shown in Figure 2, the selected e-health process is divided into four stages: patient registration and doctor allocation, providing consultation to the patient, further patient examination and discharge. In the first stage, the receptionist registers the new patient or retrieves the patient's data from the e-health system if the patient is registered already. In the second stage, the doctor commences the patient examination and stores the data related to the patient in the system, including 
laboratory results, patient medical history, referrals and prescriptions. This confirms that the doctor has examined the patient and understands the patient's condition.

In the third stage, if the patient requires further examination, such as a blood test, an X-ray, the doctor refers them to other medical departments or healthcare professionals. In the fourth stage, the hospital administrator organizes a follow-up patient visit if required, finalizes the payment and discharges the patient. The eGovernment process in the context of e-health as shown in Figure 2 illustrates how the overall health infrastructure will be improved by allowing healthcare professionals to share information and provide access to medical records. Moreover, it demonstrates how medical practices may be improved once the e-health IS is adopted and integrated with other existing eGovernment IS.

\subsection{Business goals modelling and goals analysis}

The e-Government infrastructure includes many hardware devices, software applications and networks, and is utilized by many participants with different capabilities and technical skills. In terms of the e-health process and extracting business goals from the process, modelling and analysing the goals, these different ehealth stakeholders and variety of components reduces e-health IS activities that are complex $[18,19]$. Hence, the method of modelling and analysing eGovernment goals must be reliable enough to ensure the effective administration of the rapidly changing eGovernment processes and goals $[20,6]$.

Accurately modelling the eGovernment process is the key element in deriving the IS requirements. Modelling the business process shows how different government requirements can be executed through every process to achieve the proposed goals $[14,17]$. A single eGovernment goal can carry many sub-goals that need to be identified for complete business process modelling and to accurately extract the IS requirements [15]. In this proposed method, once the health process in the context of the eGovernment environment has been identified and modelled, we then classify the sub-goals in the selected health process using the concept of the UML goal tree.

The goal tree in Figure 3 represents the sub-goals, which are extracted from the model in Figure 2. This goal tree model represents the number of eGovernment goals in the context of e-health and their related tasks. For example, goal "hospital" has two main sub-goals: "Hospital administration" and "Hospital system". The health goal "Hospital system" further sub-divided into nine sub-goals, namely, "Patient registration", "Health system integration", "Consultant", "Medical staff", "Consultation", "Medication", "Further examination", "Medical test" and "other health professionals". Moreover, this model prioritizes the goals, which helps to translate them into IS requirements. 


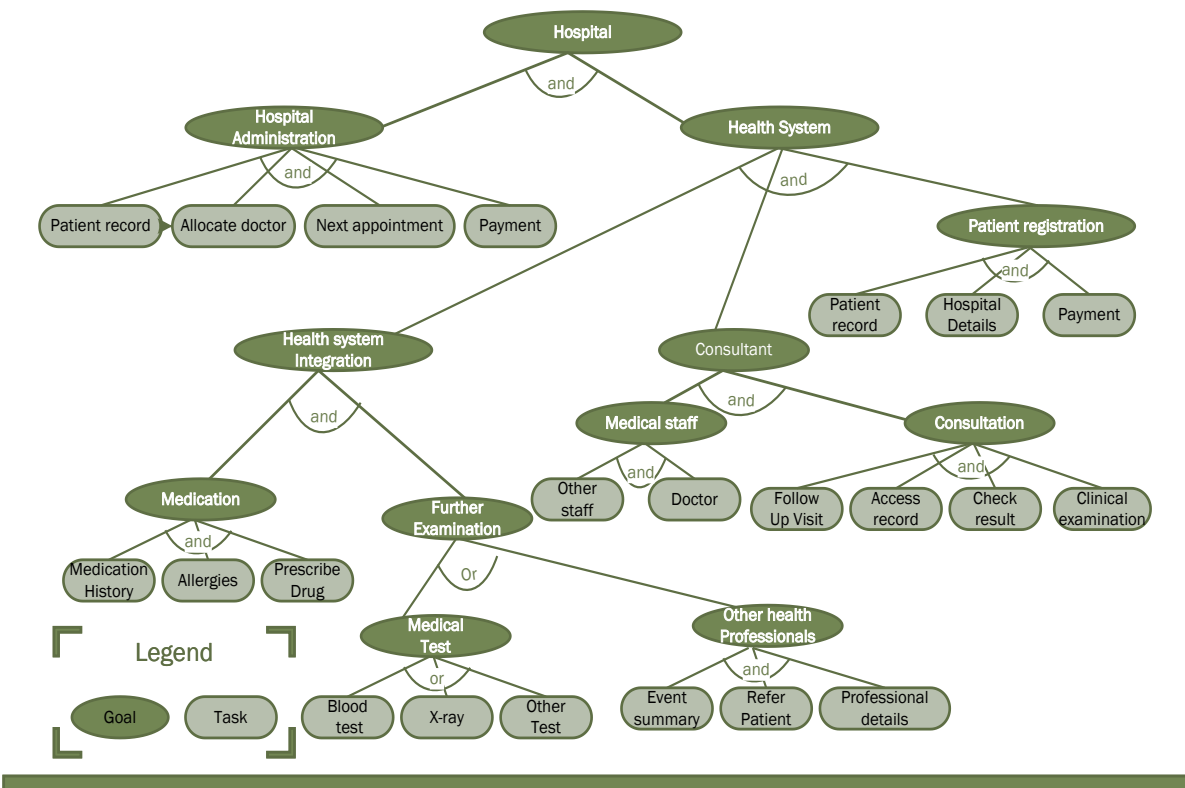

Figure 2: Identification of goals and tasks in the e-health process

Once the goals have been prioritized, we then analyze the eGovernment goals by addressing the following questions: who are the IS stakeholders, where in the eGovernment sector is the system going to be used; and why does eGovernment need this system? At this stage, the IS analysts inspect the model and label the goals and tasks to identify which ones are not important to develop from the government's perspective.

These goals and tasks are then marked with a cross and removed from the IS requirements. Figure 4 shows the analysis of the process, including the goals and their tasks. In this model, the health goals and tasks that cannot be developed technically have been removed from the model. Health goals and tasks that cannot proceed are as follows: Health goals "Medical Test" and Health tasks: "Other staff", "Clinical examination", "Prescribe drug", "Blood test", "x-ray", and "Other test". 


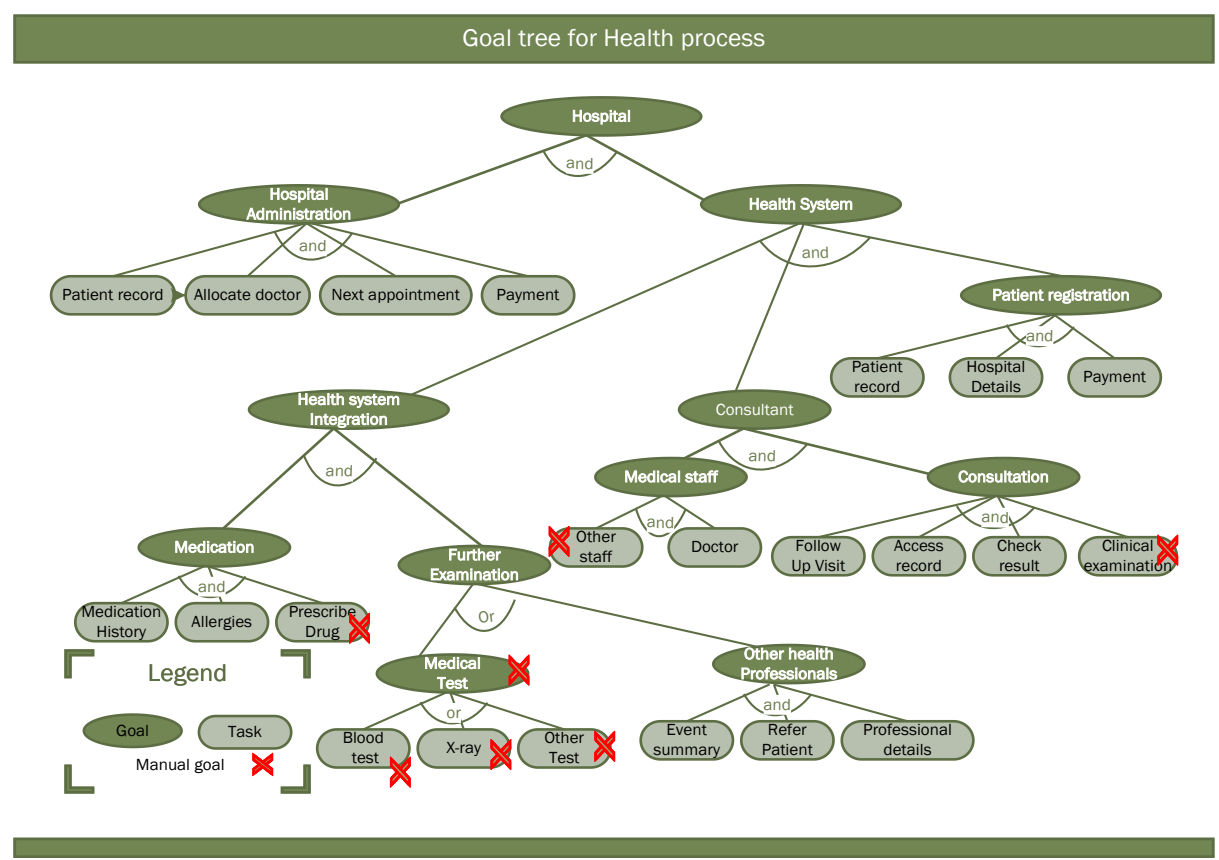

Figure 3: Analysis of e-health goals and tasks

\subsection{Derivation of IS requirements for eGovernment in the context of e-health}

Once the business goals have been extracted from the proposed e-health process and analysed, the UML use cases are obtained from the UML goal tree in Figure 4.

Figure 5 presents the UML use cases to show how IS developers can develop an ehealth system in the context of eGovernment. Use cases in this model demonstrate the complete IS requirements, which are categorized into four actors: the hospital receptionist, the hospital system, the doctor and the nurse. The hospital receptionist registers the patient's record and refers the patient to an available doctor. The doctor and nurse are the medical staff who examine the patient. The hospital system actor represents the database of the hospital, where the patient's records are stored.

The UML use cases allow the IS analysts to change or modify the IS requirements at any stage of the system development life cycle in order to remove ambiguity between the system stakeholders. IS analysts collect the details of the use case package and forward these to the developers to complete the system. The e-health developers in the eGovernment infrastructure first check the use case package to see whether the package has any duplicate records or requirements. If there are no errors, e-health IS requirements are ready to implement. At this level, the e-health IS requirements are clear and understood, which helps the developers to develop the system according to the government expectations. This ensures there is strong alignment between IS and other agencies in the eGovernment sector. 


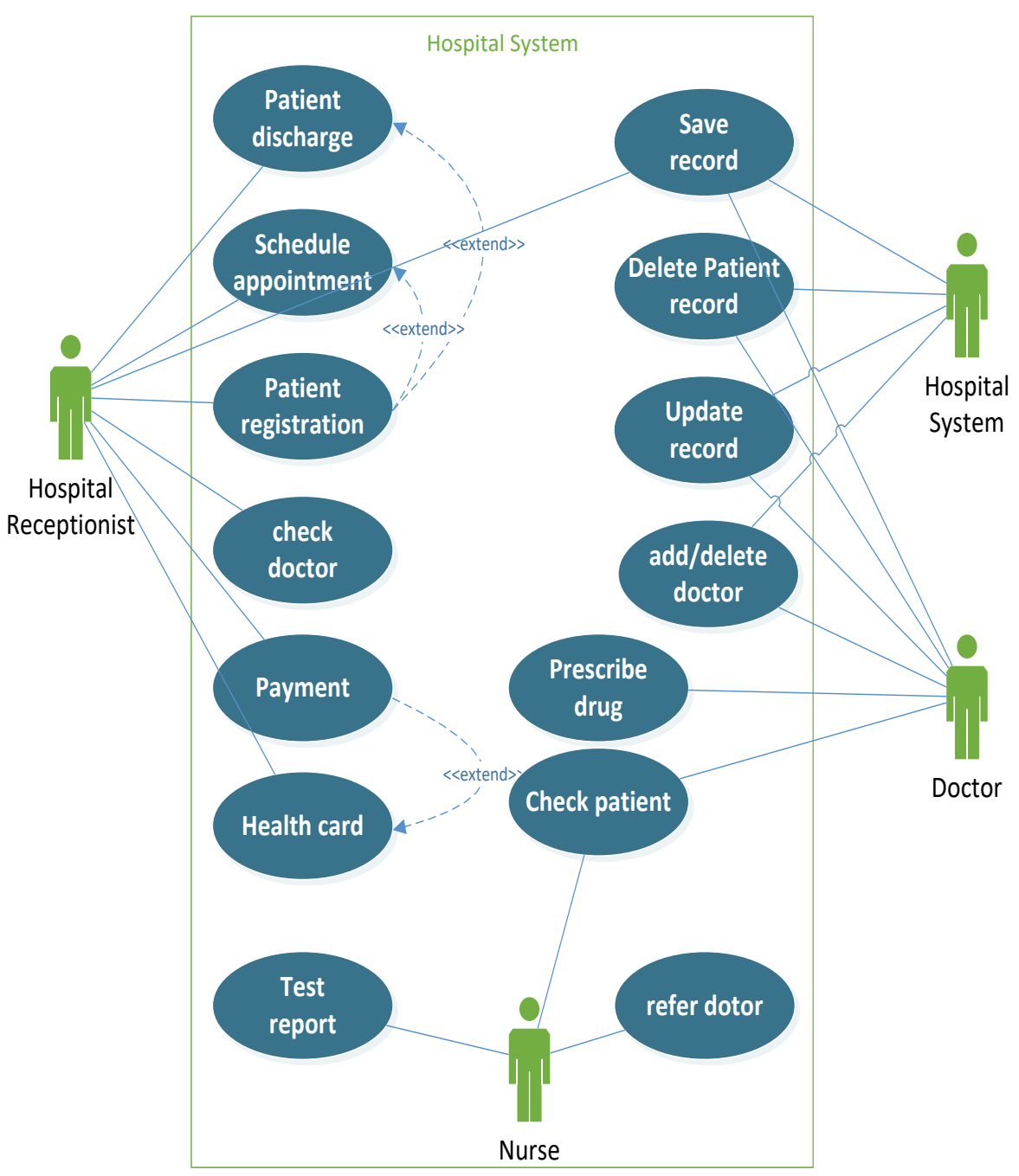

Figure 4: e-Health system requirements

\section{Conclusion and implications}

The impact of IS on numerous domains, such as education, medicine, business, engineering, governments has been enormous etc. However, rapid change in both ICT and IS fields and substantial enhancements to digital connectivity has forced governments to change their structure $[4,21]$. This is why most governments these days are reconsidering the way they work and interact, both internally and with external business organizations. This rapid change in ICT and IS has also encouraged government organizations and associations to reassess their internal and external 
relationships and dealings. Therefore, alignment between IS and other government agencies is important to establish strong working relationships.

Alignment is the process where IS and other government agencies work together to reach a common government goal. The successful process of alignment helps governments to achieve the following: effective strategic planning towards better IS support to the government, better business performance for the government, bridging the communication gap at all levels of the government, and stronger relationships between IS and other government agencies [6, 8, 9, 19].

This paper provides an alignment solution to the eGovernment sector in the context of modelling business processes and developing suitable IS. Two main implications can be derived from this paper. First, it focuses the attention of eGovernment and alignment researchers on business process modelling in order to ensure more and accurate support from IS. This proposed method shows how modelling the business environment can lead to a complete understanding of the goals and values of eGovernment in order to enhance any business process in any sector. Second, generating IS requirements from the eGovernment process is a difficult task due to the complexity of the eGovernment infrastructure, as one business process carries more than one sub-goal. This method defines how the eGovernment business process can be measured and the related business goals can be extracted.

The proposed model has one limitation. The model is validated using only one business process in e-health, therefore, it is important to evaluate and validate the proposed model with different eGovernment business processes. As one business process vary from eGovernment aim to aim and from Government sector to sector. Thus, further investigation is required in validating the model with more than one eGovernment business processes in order to enhance the effectiveness of the model.

\section{References}

1. Almajali, D., Dahlin, Z.: IT- Business strategic alignment in influencing sustainable competitive advantage in Jordan. Proceedings of the Annual International Conference on Infocomm Technologies in Competitive Strategies. (2010).

2. Asato, R., Spinola, M.D.M., Costa, I., Silva, W.H.D.F.: Alignment between the business strategy and the software processes improvement: A roadmap for the implementation. PICMET '09 - 2009 Portland International Conference on Management of Engineering \& Technology. (2009).

3. Bergeron, F., Raymond, L., Rivard, S.: Ideal patterns of strategic alignment and business performance. Information \& Management. 41, 1003-1020 (2004).

4. Berghout, E., Tan, C.-W.: Understanding the impact of business cases on IT investment decisions: An analysis of municipal e-government projects. Information \& management 50(7), 489-506(2013).

5. Bharadwaj, A., El Sawy, O.A., Pavlou, P.A., Venkatraman, N.V.: Digital business strategy: toward a next generation of insights. Mis Quarterly, 37(2),471-482 (2013).

6. Bleistein, S.J., Cox, K., Verner, J.: Validating strategic alignment of organizational IT requirements using goal modeling and problem diagrams. Journal of Systems and Software, 79(3), 362-378(2006).

7. Bubenko, J., Persson, A., Stirna, J.: EKD User Guide (2001). Dep. of Computer (2001). 
8. Charoensuk, S. Wongsurawat, W., Khang, D. B.: Business-IT Alignment: A practical research approach. The Journal of High Technology Management Research, 25(2), 132147(2014).

9. Campbell, B.: Alignment: Resolving ambiguity within bounded choices. PACIS, 54 (2005).

10.Chen, D.Q., Preston, D.S., Tarafdar, M.: From Innovative IS Strategy to Customer Value: The Roles of Innovative Business Orientation, CIO Leadership and Organizational Climate. ACM SIGMIS Database, 46(2), 8-29(2015).

11.Chen, R.S., Sun, C.M., Helms, M.M., Jih, W.J.K.: Aligning information technology and business strategy with a dynamic capabilities perspective: A longitudinal study of a Taiwanese Semiconductor Company. International Journal of Information Management. 28(5), 366-378(2008).

12.Luis, J., De Vara González, J.S.D.: Business process-driven requirements engineering: a goal-based approach, (2007).

13.Foss, N. J., Lindenberg, S.: Microfoundations for strategy: a goal-framing perspective on the drivers of value creation" The Academy of Management Perspectives 27(2), 85-102(2013).

14.Gartlan, J., Shanks, G.: The alignment of business and information technology strategy in Australia. Australasian journal of information systems. 14(2), (2007).

15.Jorfi, S., Jorfi, H.: Strategic operations management: Investigating the factors impacting ITbusiness strategic alignment." Procedia-Social and Behavioral Sciences. 24, 1606-1614 (2011).

16.Jaskiewicz, P., Klein, S.B.: The impact of goal alignment and board composition on board size in family businesses. Journal of Business Research. 60(10), 1080-1089(2007).

17.De la Vara González, J.L., Diaz, J.S.: June. Business process-driven requirements engineering: a goal-based approach. In Proceedings of the 8th Workshop on Business Process Modeling. (2007).

18.Lehtola, L., Kauppinen, M., Kujala, S.: April. Requirements prioritization challenges in practice. In International Conference on Product Focused Software Process Improvement. 497-508, (2004).

19.Martinez-Simarro, D., Devece, C., Llopis-Albert, C.:How information systems strategy moderates the relationship between business strategy and performance. Journal of Business Research. 68(7), 1592-1594(2015).

20.Meijer, A., Thaens, M.: Alignment 2.0: Strategic use of new internet technologies in government. Government Information Quarterly. 27(2), 113-121(2010).

21.Mirchandani, D.A., Lederer, A.L.: The impact of core and infrastructure business activities on information systems planning and effectiveness. International Journal of Information Management. 34(5), 622-633(2014).

22.Ningsih, K.R., Sembiring, J., Arman, A.A., Wuryandari, A.I.: September. Developing IT investment management framework of government institution. In Advanced Computer Science and Information Systems (ICACSIS). International Conference on. 237-242(2013).

23.Odiit, M.C.A., Mayoka, G.K., Rwashana, A.S., Ochara, N.M.: September. Alignment of Information Systems to Strategy in the Health Sector Using a Systems Dynamics Approach. In Proceedings of the Southern African Institute for Computer Scientist and Information Technologists Annual Conference 2014 on SAICSIT 2014 Empowered by Technology. 38(2014).

24.Raup-Kounovsky, A., Canestraro, D.S., Pardo, T.A., Hrdinová, J.: IT Governance to fit your context: Two US Case Studies. In Proceedings of the 4th International Conference on Theory and Practice of Electronic Governance. 211-215(2010).

25.Ryu, H.S., Lee, J.N., Choi, B.: Alignment Between Service Innovation Strategy and Business Strategy and Its Effect on Firm Performance: An Empirical Investigation. IEEE Transactions on Engineering Management. 62(1), 100-113(2015).

26.Ullah, A., Lai, R.: Managing Security Requirements: Towards Better Alignment Between Information Systems And Business.PACIS. 195 (2010). 
27.Ullah, A., Lai, R.: A requirements engineering approach to improving IT-Business alignment. Information Systems Development, Springer: 771-779(2011).

28.Ullah, A., Lai, R.: A systematic review of business and information technology alignment.ACM Transactions on Management Information Systems (TMIS). 4(1): 4(2013).

29.Veres, C., Sampson, J., Bleistein, S.J., Cox, K., Verner, J.: March. Using semantic technologies to enhance a requirements engineering approach for alignment of IT with business strategy. In Complex, Intelligent and Software Intensive Systems, 2009. CISIS'09. International Conference on. 469-474(2009).

30.White, S. A., Miers, D.: BPMN modelling and reference guide: understanding and using BPMN. Future Strategies, (2008)

31.Zowghi, D., Jin, Z.: A framework for the elicitation and analysis of information technology service requirements and their alignment with enterprise business goals. In Computer Software and Applications Conference Workshops (COMPSACW), IEEE 34th Annual 269272(2010).

32.Rakgoale, M., A., Mentz, J., C.: Proposing a Measurement Model to Determine Enterprise Architecture Success as a Feasible Mechanism to Align Business and IT. International Conference on Enterprise Systems (ES). 214-224(2015).

33.Dardenne R., Lamsweerde A., Fickas S.V.: Goal-directed Requirements Acquisition, Science of Computer Programming. 3-50(1993).

34.Gordijn J., Yu E., Raadt B.V.D.: E-Service Design using I* and e3 value Modeling, IEEE Software journal. 23(3), 26-33(2006).

35.Ellis C.A., Wainer J.: Goal-Based Models of Collaboration, Collaborative Computing, 6186(1994).

36.Card S.K., Moran T.P., Newell A.: The Psychology of Human-Computer Interaction., Hillsdale, NJ, Erlbaum, USA. (1983). 